21 Steinbock B. Recovery from persistent vegetative state? The case of Carrie Coons. Hastings Cent Rep 1989;19:14-5.

22 Najenson T, Sazbon L, Fiselzon J, Becker E, Schechter I. Recovery of communicative functions after prolonged traumatic coma. Scand $\mathcal{f}$ Rehabil Med 1978;10:15-21.

23 Haig AJ, Reuss JM. Recovery from vegetative state of six months' duration associated with Sinemet (levodopa/carbidopa). Arch Phys Med Rehabil 1990;71:1081-3.

24 May PG, Kaelbling R. Coma of a year's duration with favourable outcome. Dis Nerv Syst 1968:29:837-40.

25 Levin HS, Saydjari C, Eisenberg HM, Foulkes M, Marshall LF, Ruff RM, et al. Vegetative state after closed head injury: a traumatic Data Bank report. Arch Neurol 1991:48:580-5.

26 Higashi K, Hatano M, Abiko S, Ihara K, Katayama S, Wakuta Y, et al. Five year follow up study of patients with persistent vegetative state. $\mathcal{f}$ Neuro Neurosurg Psychiatry 1981;41:552-4.

27 Rosenberg GA, Johnson SF, Brenner RP. Recovery of cognition after prolonged vegetative state. Ann Neurol 1977;2:167-8.

28 Arts WFM, Van Dongen HR, Duin JVH-V, Lammens E. Unexpected improvement after prolonged posttraumatic vegetative state. $f$ Neurol Neurosurg Psychiatry 1985;48:1300-3

29 Tanheco J, Kaplan PE Physical and surgical rehabilitation of patient after 6 year coma. Arch Phys Med Rehabil 1982;63:36-8.

304 out of 10 doctors back euthanasia law change (news). BMA News Review 1993;19:9. (April 1993.)

\title{
Patients in the persistent vegetative state: problems in their long term management
}

\author{
Keith Andrews
}

\begin{abstract}
Physicians responsible for the long term management of patients in the persistent vegetative state face several problems. These include deciding whether tube feeding is treatment or nutritional care, whether withdrawal of tube feeding is an appropriate form of management, what clinical advantage there is in active treatment; at what level of awareness can a patient be said to have a quality of life; and who should determine a patient's right to die. These problems are determined more by social, legal, emotional, cultural, religious, and economic forces than by clinical facts.
\end{abstract}

Patients in the persistent vegetative state have no obvious cognitive function and are generally thought to have a very poor prognosis. These factors have led to several inferences being drawn about such patients which have implications for their management: that they have no quality of life; that there is no advantage in keeping them alive; that they cannot feel distress if, say, their food is withdrawn; and that others must make decisions on their behalf. The recent case when the High Court was asked to agree to the removal of feeding from a young man in the persistent vegetative state has highlighted these issues. In this paper I address some of the problems faced by physicians responsible for the long term management of people with severe or profound disabilities.

\section{The case of Anthony Bland}

Anthony Bland was aged 18 when he suffered severe anoxic brain damage during the disaster at Hillsborough football ground three years ago. He remained in a vegetative state for three years and died when his nasogastric feeding was withdrawn. All of the expert witnesses in the court case agreed that there was no hope of any recovery, and the local health authority, supported by Anthony's parents, sought the court's permission to stop feeding by nasogastric tube to allow Anthony to die. This was the first case to come to the courts in England, although the principle has been accepted in some American states, Canada, and some other countries.

\section{IS FEEDING A TREATMENT?}

The main basis of the argument for the withdrawal of feeding was that feeding was a treatment and that it was acceptable for doctors not to treat someone with no hope of recovery. At the trial I suggested that treatment, by its very nature, was given to treat an abnormality and said that I could not understand what abnormality the food was supposed to be treating-its purpose being to supply normal nutrition to an otherwise healthy body. The arguments depended on the fact that the feeding required technology (the gastrostomy tube), special food, supervision by a dietitian, and insertion of the tube by a trained nurse. Although it is standard practice to provide prescribed preparations of food for nasogastric tubes, there is no reason, apart from the time needed for its preparation, why liquidised "normal" food should not be used. Similarly a dietitian's advice is desirable but not essential-few of us need a dietitian to advise us on our nutritional intake unless we require a special diet for a metabolic or primary nutritional disorder. It is, however, accepted that the tube is an abnormal or, more accurately, a technical method of feeding a patient. The tube is a method of overcoming a physical block to allow the provision of normal food to an otherwise healthy body. The tube is therefore the treatment, the food is not. Neither can be effective without the other, however, and the package, of tube and food, must therefore be the treatment.

\section{DEATH BY NATURAL CAUSES?}

Leaving aside these niceties, the purpose of withdrawing the nasogastric tube, and therefore the food, would be to end the life of the patient. In the trial much emphasis was placed on the opinion of most of the expert witnesses that if the tube was removed the cause of the death would not be the doctor but the original brain damage. Another point of view, however, is that the act of removing the tube would result in starvation, death being due to damage to previously healthy tissues secondary to the patient not being able to gain access to food. The same situation would arise in the "locked-in" syndrome, in which a patient is cognitively intact but totally paralysed because of a lesion in the pons, or in a case of fracture of all four limbs, as in a skiing accident. In such cases a patient would starve to death if food was not provided, but would the death be thought to be due to natural causes-brain damage or fractured limbs-or due to the withholding of food?

\section{A patient who has no quality of life?}

Quality of life is difficult to define, especially for someone unable to express any views. This is relevant because a person's quality of life is something which only that individual can decide-it depends on concepts of handicap rather than disability. Whatever our opinion of someone's quality of life, if that person disagrees then we must be wrong. An extreme point of view could be that patients in the persistent vegetative state have a good quality of life, since they are fed, watered, warm, safe, and without worries. Another view is that if they are unable to appreciate anything

\section{Putney, London}

Keith Andrews, director of

medical and research services

$B M 7$ 1993;306: 1600-2

\section{.}

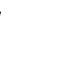


then they cannot have a good or a bad quality of life. What we really mean is that we interpret their quality of life as being poor-it is our quality of life which is affected.

\section{No advantage in keeping a patient alive?}

If a patient has no awareness, what advantage is there in the patient continuing to live and our continuing to provide food? The term advantage is difficult to define, although possibly most people think they know what it means. In the case of Anthony Bland the term used was "clinical advantage." When I said that I was not sure what this meant, the judge made it clear that he interpreted this as recovery. Under this definition there is no doubt that the continuing feeding of most patients in the persistent vegetative state has no clinical advantage since there can be no recovery. This has serious implications for many other disabled people. In rehabilitation there are three goals: to aid recovery, to maintain existing levels of ability, and to slow down rates of deterioration in degenerative disorders. There is, therefore, no clinical advantage in much of the rehabilitation for patients with disabling disorders since there is no recovery. Millions of disabled people will probably disagree, and the implication of clinical advantage-if based on recovery - must be of concern to those with multiple sclerosis, stroke, Huntington's disease, cancer, rheumatoid arthritis, and so on.

\section{What is a worthwhile level of recovery?}

I am often challenged about what I and my colleagues hope to achieve in our care of patients in the persistent vegetative state. If I am honest there are times when I wonder myself. My official answer is to prevent distressing complications (contractures, pressure sores, urinary tract calculi, and undernutrition), to aim for some recovery (that word again), and to provide an optimal quality of life in the limits of a patient's ability. Few patients remain totally unresponsive after undergoing a rehabilitation programme, but many will still be severely disabled. This raises questions about whether such efforts should be made to achieve some level of response and whether severe disability is a worthwhile achievement. The difficulty for the rehabilitation specialist is no different from that of the neurosurgeon or intensive care specialist -we do not know the outcome of a treatment until after we have tried it. Our introduction of a rehabilitation programme to patients in the persistent vegetative state has recently resulted in some successes which were previously not believed possible.' On the other hand, what do we make of the young man who remains totally dependent on others for all his needs but smiles all day and apparently enjoys watching simple activities and being part of a group? What do we make of the young man with anoxic brain damage who was in the persistent vegetative state for three years, but who has recently started smiling on request, laughing appropriately at television cartoons, and showing pleasure in his surroundings? Is there no clinical advantage in continuing to feed these patients?

\section{No distress if food is withheld?}

In all of the above examples there was some awareness and therefore the possibility of appreciating pain: the patients would no doubt demonstrate some distress if food was withdrawn. Very few patients in the persistent vegetative state are so severely brain damaged that they demonstrate no response, and most respond to pain either by withdrawing or grimacing. Since the first level of awareness of pain is thought to be in the thalamus such a response to pain does not necessarily mean that a patient is aware of the pain. If we want to be particular we could ask, "How do you know?" After all, the only way any of us can communicate that we find any stimulation unpleasant-or pleasant for that matter-is by speech or some physical gesture. If we are paralysed we can no longer indicate our feelings. In the case of the persistent vegetative state we therefore have to rely on our clinical experience and our understanding of neurology, which is not $100 \%$ reliable: when Carrie Coons's feeding tube was removed on the order of a court she woke and started feeding; and when Karen Quinlan's respirator was switched off she continued to breathe spontaneously for another 10 years. These unsuccessful attempts to end patients' lives were based on the available knowledge of the severity of their brain damage. Someone once said, "If the brain was so simple we could understand it, we would be so simple that we couldn't."

The question of distress is obviously important. If we are going to decide not to keep a patient alive and to withhold food and water, no one would want the patient to suffer distress. If there is no cortical function then we assume that the patient cannot be aware of the distress. While recognising that a withdrawal response to pain is a basic reflex which has a functional value of removing the stimulated part from danger, it is more difficult to see how facial grimacing in response to pain stimulation of the leg can have a useful reflex purpose except to alert other members of the species to the possibility of danger. Is it possible that we have given too little thought to a patient's lower brain functions as part of the person we are caring for?

I have seen only one patient in the persistent vegetative state die of starvation (because oesophageal stricture prevented reinsertion of a nasogastric tube). She took three weeks to die and became more alert, constantly awake, and agitated-presumably due to the release of brain stimulating chemicals in response to hypoglycaemia. It is one thing to state that she could not have felt any distress because she had a damaged cortex, it is another to be fully convinced (and to convince her carers) that there really was no suffering. Under such circumstance heavy sedation would probably be worthwhile, but this would be making a positive intervention in a process that could otherwise be regarded as being due to passive or negative intervention.

\section{Who decides if a patient should die?}

Even if we assume that it is logical to assist the death of a patient, who is going to make the decision? The physician in charge should reach an agreement with the patient's family and any other carers that it would be appropriate to withdraw feeding. Indeed, the request may come from relatives. What seems to be clear is that no decision should be made without the agreement of relatives. There is, however, a major problem if members of a patient's family hold conflicting views. There is also the question of whether even a patient's family has the right to decide whether that patient lives or dies. Our main duty is, presumably, to act in the best interests of the patient. If we have two identical patients in the persistent vegetative state and the family of one wants the patient's feeding tube removed while the family of the other is strongly opposed to removal of the tube, should we respect the wishes of both families? If we do can we truly be said to be acting on behalf of the patient? If so, which one? What implication does this have for other patients who are not in the persistent vegetative state but whose families think that they would be better off dead (such as those who are conscious but who have severe brain 
damage, those who are mentally handicapped for other reasons, and those with dementia or other "incurable" chronic disorders)?

We seem to be progressing down the road of accepting involuntary euthanasia before voluntary euthanasia has been accepted legally. It is unlikely that starvation would be regarded as an acceptable way of assisting dying in voluntary euthanasia, so should we even consider this method for involuntary euthanasia?

\section{Conclusion}

I have asked questions to which I have no answers. The factors influencing them are rarely clinical but depend much more on the attitude of society to the care of disabled people and to social, legal, emotional, political, cultural, religious, and economic forces.
Irrespective of whether it is legal to withhold food from patients in the persistent vegetative state, these problems will continue to face physicians responsible for the long term care of such severely disabled people. Patients and their families may now have to be reassured that the withholding of food will not be automatic. Before such actions are considered it is essential that a full rehabilitation programme should be offered to patients in the early stages of the persistent vegetative state to give them the optimal chance of recovery. And we should be absolutely certain that our diagnosis is correct.

1 Andrews K. Recovery of patients after four months or more in the persisten vegetative state. $B M \mathcal{F}$ 1993;306:1597-600

(Accepted 27 April 1993)

\section{Patients in the persistent vegetative state: a response to Dr Andrews}

\section{Raanan Gillon}

The central moral objective of medicine-adhered to by doctors and health care workers since Hippocratic times - is to produce net medical benefit for the patient with as little harm as possible. Today we may add to that Hippocratic objective the moral qualifications that we should pursue it in a way that respects people's deliberated choices for themselves and that is just or fair to others (whether in the context of distribution of scarce resources, respect for people's rights, or respect for morally acceptable laws). This moral frameworka sort of medico-moral mission statement-is consistent with the formal quartet of moral principles introduced to medical ethics by Beauchamp and Childress, which I discuss elsewhere, ${ }^{2}$ and is useful in analysing the various ethical questions posed by Andrews in his two papers in this issue of the $B M \mathcal{F} .^{34}$

\section{Deciding what is net medical benefit}

There are those who believe that preservation of life-any sort of life-is a benefit and worth striving for. For them even maintaining the life of a patient in the persistent vegetative state (when the patient is reliably believed to be in a state of permanent unconsciousness) is a medical benefit worth striving for. Such people argued that Tony Bland-an indisputable example of a patient in the persistent vegetative state, which was reliably believed to be permanent-should have been kept alive, opposing the recommendations of his parents and of his consultant and medical team. Others-I suspect a large majority-believe that continuance of life is a morally neutral means to an endgood only if the continuing life is a "good life." For many of us this means a life that, from the person's own perspective, is worth living.

It is important for health care workers and their patients and potential patients (and increasingly their potential purchasers) to know which view they hold. If they are members of the vitalist persuasion, who favour prolonging life regardless of its quality, they should surely make this clear so that those who reject such views may be warned and take appropriate avoiding action. For my own part, and to declare my own bias, I detest the prospect of being kept alive in any severely disabled state in which I would no longer be able to make deliberated decisions for myself unless there was reason to believe that I had a good chance (preferably better than one in two and certainly better than one in
10) of recovering my ability to be an autonomous agent.

This is of course a major dilemma for members of the medical profession who are of the vitalist persuasionthey presumably feel bad and wrong in "letting go" any human life that could be prolonged. But in trying to resolve their dilemma I believe that they should use the medico-moral framework above and ask themselves whether a patient would, on deliberation have considered the sort of life that seems the probable outcome a life worth living. A variety of evidence may be relevant in answering the question, particularly any advance directives given by the patient. If the patient's views are unavailable the evidence of the patient's proper proxies (usually close relatives or friends) about his or her best interests may be sought. However, even if the proxies believe that preserving the life of the patient in the persistent vegetative state is worthwhile and the patient had given an advance directive to that effect there remains the question of justice. Is the allocation of resources to preserve a life of absent or probably permanently severely impaired consciousness fair or just given that this will deny those resources to all other possible claimants?

Further questions about the treatment of patients in the persistent vegetative state

In his first paper Dr Andrews raises other questions, which I shall consider only briefly-I have addressed some of them more thoroughly elsewhere. ${ }^{5}$

Is artificial hydration and nutrition a medical treatment? Yes, because it is an intervention to prolong life that requires medical skills (imagine leaving to medically unskilled people the nutrition and hydration of long term unconscious people for whom there was a reasonable prospect of good recovery).

Does it matter? Not much. What matters is whether it is care: care requires the intention and prospect of benefit, which takes us back to the question of whether the mere prolongation of life is a benefit, as distinct from a life that the patient considers worth living.

Is the purpose of withdrawing treatment, including hydration and nutrition, to end the life of the patient? It depends on the intention of the decision maker. There is no requirement for such an aim because it is perfectly possible that the purpose of such a decision is only the withdrawal of useless, non-beneficial treatment- 